\title{
Behaviour of Extended Endplate Connection with Mild and High Strength Steel
}

\author{
Omnia F. Kharoob, Mahmoud H. El-Boghdadi, Sarah A. Yousef \\ Structural Engineering Dept., Faculty of Engineering, Tanta University, Tanta, Egypt
}

Email: ${ }^{1}$ omnia_m102010@f-eng.tanta.edu.eg, ${ }^{2}$ mahmoud.el-boghdadi@f-eng.tanta.edu.eg. ${ }_{2}{ }^{3}$ sarah.yousef@f-eng.tanta.edu.eg

\begin{abstract}
This paper uses the multi-purpose software ABAQUS to create a three-dimensional finite element model of an extended end plate connection to analyze and compare the behaviour of mild steel and high-strength steel endplate connections. The numerical model's results are calibrated against reported experimental results to ensure that it can simulate and analyze both the overall and detailed behaviour of different types of bolted endplate steel connections. The results of the study compare and analyze the moment-rotation relationships and the behaviour characteristics of the connection with mild steel and high strength steel. A parametric study is then carried out using the verified FEM to examine many parameters such as endplate thickness, bolt diameter, and steel grade of the endplate. The results of this study indicate that for extended endplate connections, increasing the endplate thickness or the bolt diameter leads to a marked increase of both the strength and the stiffness but it reduces the ductility of the connections. Also, increasing the endplate steel grade results in higher strength but lower ductility.
\end{abstract}

Keywords: Extended End Plate; High Strength Steel; MomentRotation

\section{INTRODUCTION}

Bolted end-plate steel connections have grown in popularity due to their ease of fabrication. Extended end-plate connections are commonly used in steel structures as moment resistance connections and as an alternative to fully welded ones in steel frames. Engineers and scientists have been interested in the problem of connection flexibility and its effect on the behaviour of steel structures for over 90 years. Since the concept of perfect rigid or pinned is purely theoretical, end-plate connections are generally known as semi-rigid joints. The classification of these connections should be based on the relationship between the moment transmitted by the connection and their rotation in the plane of connection. According to Eurocode 3 [1] and the majority of studies, it can be classified based on rotational stiffness, strength, and ductility. Furthermore, steel with a nominal yield stress equal to or greater than $460 \mathrm{MPa}$ is classified as high strength steel, according to the implications of the current European Standard for steel structures Eurocode 3 [1]. Owing to its economic advantages over mild steel, which is hot rolled carbon steel with standard strength, high strength steel (HSS) has been used in many structures around the world in the last decade, such as the Beijing Bird's Nest Olympic Stadium, the New York Freedom Tower and the French cable-stayed roadbridge Millau Viaduct. As a result, HSS is gaining popularity in the market of constructional steel structures.
Many analytical and experimental studies on end-plate steel connections were carried out in order to establish an accurate method for predicting the rotational behaviour of the connection under monotonic and cyclic loadings. In 2007, Dabaon et al. [2, 3] proposed a three-dimensional Finite Element (FE) model, with ANSYS software [4], for the analytical investigation of the effect of loads acting in the minor direction on the behaviour of semi-rigid joint in the major direction. In 2009, Dabaon et al. [5] carried out five full-scale tests on semi-rigid space steel and composite extended endplate joints and proposed a three-dimensional FE model using ANSYS software [4] to investigate the behaviour of space steel and composite semi-rigid joints. In 2008, Shi et al. [6] described the development of a FE numerical model with the ability to simulate and analyze the mechanical behaviour of different types of beam-column end-plate connections in which all of the bolts were pretensioned. Also, Qiang et al. [7] in 2014 presented a numerical analysis on HSS endplate connections under fire conditions carried out with ABAQUS [8] in order to understand the behaviour of HSS endplate connections under fire conditions. Shi et al. [9] in 2010, described tests under monotonic loads of eight specimens of beam-to-column bolted end-plate connections with I-section members and various details in order to investigate the influences of these details on joint behaviour. Coelho and Bijlaard discovered [10] in 2007 that HSS S690 endplate connections satisfy the design requirements for resistance and achieve acceptable rotation demands. In 2014, Qiang et al. [11] performed full-scale experiments on beamto-column HSS endplate connections and discovered that a proper thinner HSS endplate would improve the connection's rotation capacity both at ambient and elevated temperatures, thus achieving nearly the same moment resistance as a mild steel endplate connection.

The first goal of this paper is to create a reliable threedimensional FE model for the analysis of bolted end-plate steel connections and to model contact between different surfaces, and then to compare the results with those of previously published experiments. The second goal is to perform a detailed parametric study using the proposed FE model to investigate the effect of various parameters on the behaviour of bolted extended end-plate connections.

This paper describes a numerical investigation of beam-tocolumn mild and high strength steel extended endplate connections using the commercial package ABAQUS [8]. Following that, the main characteristics of the FE model, such 
as geometry, materials, mesh, element, contact interaction, and analysis progress are explained in detail afterwards.

\section{FINITE ELEMENT MODEL DESCRIPTION}

The FE software package ABAQUS 6.14 [8] was employed to numerically simulate the behaviour of mild steel extended endplate connections. Nonlinearities of both material and geometry were considered. All parts of the models are presented in detail in the following subsections.

\section{A. Mesh generation and element type}

Steel beam, column, endplate, rib stiffeners of endplate, column stiffeners, and high-strength bolts are the components of a steel extended endplate connection. A typical extended endplate connection is shown in Fig. 1. The whole connection was modelled using C3D8I solid elements.

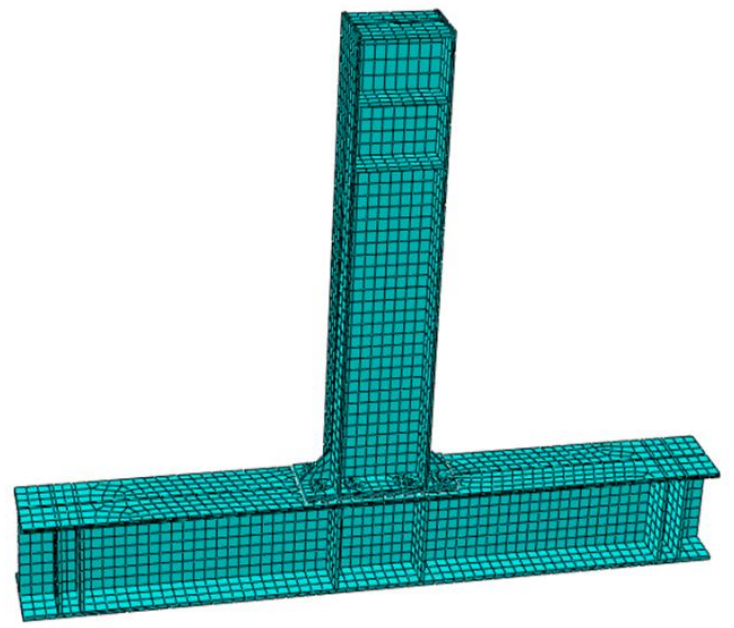

Fig. 1: A 3D solid FE model of an extended endplate connection

\section{B. Contact modeling}

When surfaces are in contact, they usually transmit shear as well as normal forces across their interface. There is generally a relationship between these two force components. This relationship, known as friction between the contacting bodies, is typically expressed in terms of stresses at the bodies' interface.

Experiments on steel endplate connections have shown that under lateral forces, the endplate tends to separate from the column flange in the tensile zone, leading to an increase in residual bending deflection.

The contact pairs in the endplate connection comprised the bolts-to-column flange, column flange-to-endplate, endplateto nuts, and bolt shanks-to-bolt holes, see Fig. 2, where the red contact surfaces are master surfaces, while the purple ones are slave ones. The nuts were tied to the bolt shanks, as shown in Fig. 2. To fully transfer the load, all contact surfaces used surface-to-surface contact with a small sliding option.

The properties of the contact surfaces are defined in the "Interaction Property Manager" of the "Interaction" module [8]. The contact properties of contact surfaces comprise two different parts: tangent interaction and normal interaction.
"Hard contact" is used for the normal interaction, which is used to simulate the extrusion phenomenon between bolts and plates. Hard contact signifies that no penetration is allowed, and no tensile forces will be transmitted. Furthermore, there is no limit to the magnitude of contact pressure that can be transmitted when the surfaces are in contact. For the tangent interaction, "Penalty friction" has been used, with friction coefficient of 0.44 [6,7].

\section{Material modelling}

For both tension and compression, structural steel components such as the steel beam, steel column, and bolts were modelled as an isotropic elastic-plastic material. Yield stress and ultimate tensile strength of the steel beam as well as Young's modulus $(E)$ are obtained from the original publications. Poisson's ratio of 0.3 was assumed.

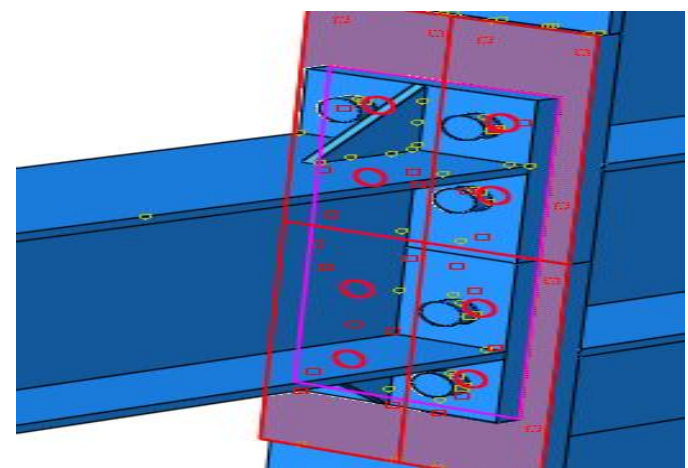

(a) Contact between the end-plate and column flange

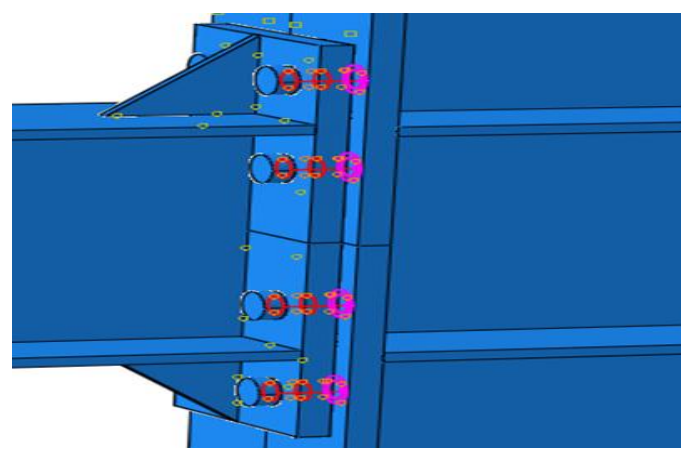

(b) Tie constraints between bolt shanks and nut Fig. 2: Contact pairs in FE model

\section{VERIFICATIONS OF THE MODEL WITH PREVIOUS WORK}

In order to verify the capability of the suggested FE models to model the beam-to-column steel bolted connections accurately, typical quasi-static tests of steel extended endplate connections were selected from the literature.

\section{A. Tests of mild steel}

Shi et al. [9] used monotonic loads to test a series of eight full-scale structural steel beam-to-column endplate moment connection specimens. Endplate thickness, bolt diameter, endplate rib stiffener, column stiffener, flush type, and extended endplate were the parameters studied. Figure 3 shows the typical extended endplate connection used for testing. During the testing, the specimens' out-of-plane deformations were restrained. These eight specimens were all beam-to-column 
connections that originated from typical multi-storey steel frames.

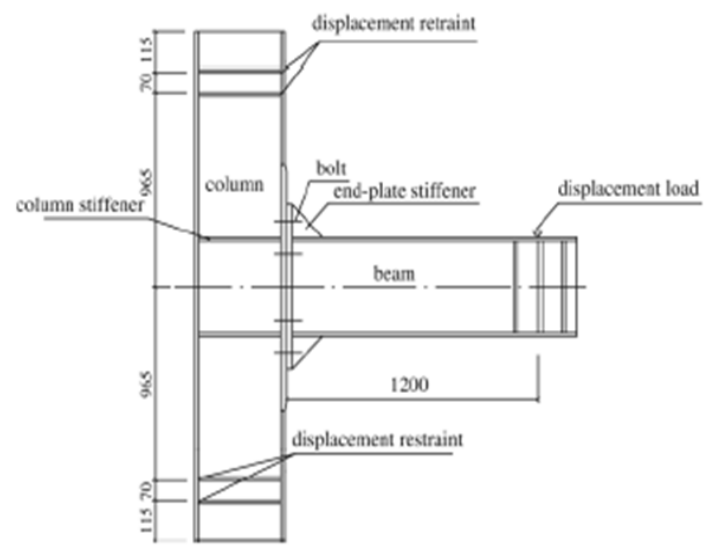

Fig. 3: Extended endplate connection Shi et al [9]

Column and beam depths, web thicknesses, and flange thicknesses are $300 \mathrm{~mm}, 8 \mathrm{~mm}$, and $12 \mathrm{~mm}$, respectively, and the column and beam widths are $250 \mathrm{~mm}$ and $200 \mathrm{~mm}$, respectively. The thickness of the column flange was taken the same as the thickness of the endplate within a range of 100 $\mathrm{mm}$ above and below the endplate's extension edge. The column stiffener and endplate extended stiffener have thicknesses of $12 \mathrm{~mm}$ and $10 \mathrm{~mm}$, respectively. The specimens tested by Shi et al. [9] were fabricated from Q345 steel. For specimen SC3, the bolts used were of $20 \mathrm{~mm}$ shank diameter and the applied pretension force in the bolts was 185 $\mathrm{kN}$, whereas for specimen SC6, the bolts used were of $24 \mathrm{~mm}$ shank diameter and the applied pretension force in the bolts was $251 \mathrm{kN}$. The material parameters are shown in Table 1. According to the numerical simulation results of Shi et al. [6], the coefficient of friction between steel surfaces was considered as 0.44 .

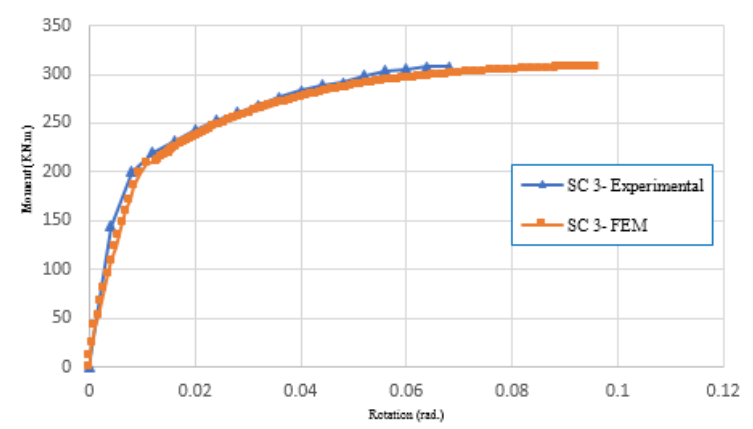

(A) $\mathrm{SC} 3$

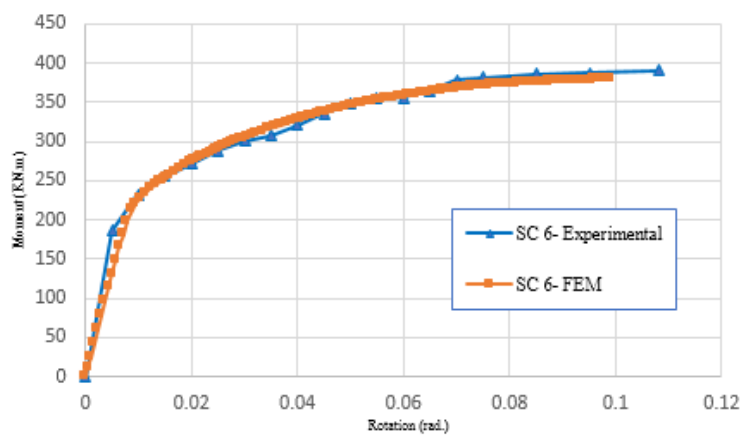

/(B) SC 6

Fig. 4: Comparison of measured results (by experimental work [9]) and predicted results (by FEM) for extended steel endplate connection.

Figure 4 and Table 2 illustrate a comparison between the moment-rotation curves predicted by the adopted numerical model and those obtained experimentally by Shi et al. [9] for bolted endplate connections. The figure clearly shows that the adopted numerical model can accurately and efficiently simulate and analyze the overall behaviour of extended endplate connections of this type, including the carrying capacity and the moment-rotation relationships.

Comparisons of experimental failure modes with those obtained by FE analysis for the specimens are shown in Fig 5, where the local deformations of the end-plate, column flange and end-plate stiffener are clearly shown. It can be observed that good agreement exists between the numerical and experimental final deformation of connections.

B. Tests of High strength steel

Qiang et al. [11] carried out full-scale tests on beam-tocolumn high strength steel endplate connections. A typical flush endplate connection used for tests is shown in Fig. 6. The endplates are made of high strength steels (S690 and S960) while the beam and column are made of mild steel Q345. The beam sections used in this study are HW300 $\times 300$ (the depth, web thickness, width, and flange thickness of the beams are $300 \mathrm{~mm}, 10 \mathrm{~mm}, 300 \mathrm{~mm}$, and $15 \mathrm{~mm}$, respectively) while the column sections are HW400 $\times 400$ (the depth, web thickness, width, and flange thickness of the columns are $428 \mathrm{~mm}, 20$ $\mathrm{mm}, 407 \mathrm{~mm}$, and $35 \mathrm{~mm}$, respectively). The load bearing capacities of the connections are designed to be similar, while the endplate materials and thicknesses vary. An overall description of stress-strain curves of bolts and various structural steels is presented in Fig. 7.

TABLE 1

MATERIAL PARAMETERS

\begin{tabular}{cccc}
\hline Material & $\begin{array}{c}\text { Young's Modulus } \\
\left(\mathrm{N} / \mathrm{mm}^{2}\right)\end{array}$ & Yield stress $\left(\mathrm{N} / \mathrm{mm}^{2}\right)$ & 391 \\
\hline $\begin{array}{c}\text { Steel } \\
(t \leq 16 \mathrm{~mm})\end{array}$ & 190707 & 363 & 559 \\
\hline $\begin{array}{c}\text { Steel } \\
(t>16 \mathrm{~mm})\end{array}$ & 204228 & 537 \\
\hline Bolts (M20) & 206000 & 995 & 1160 \\
\hline Bolts (M24) & 204228 & 975 \\
\hline
\end{tabular}


TABLE 2

COMPARISON OF MEASURED RESULTS FOR EXTENDED STEEL ENDPLATE CONNECTION

\begin{tabular}{ccccccc}
\hline \multirow{2}{*}{$\begin{array}{c}\text { Specimen } \\
\text { Number }\end{array}$} & \multicolumn{3}{c}{ FEM Result } & \multicolumn{3}{c}{ Test Result } \\
\cline { 2 - 6 } & $\begin{array}{c}S_{j . \text { ini }} \\
{[\mathrm{kN} . \mathrm{m} / \mathrm{rad}]}\end{array}$ & $M_{\max }[\mathrm{kN} . \mathrm{m}]$ & $\varphi_{\max }(\mathrm{rad})$ & $\begin{array}{c}S_{\text {j.ini }} \\
{[\mathrm{kN} . \mathrm{m} / \mathrm{rad}]}\end{array}$ & $M_{\max }[\mathrm{kN} . \mathrm{m}]$ & $\varphi_{\max }(\mathrm{rad})$ \\
\hline SC 3 & 45620 & 308.0 & 0.095 & 49093 & 308.3 & 0.067 \\
\hline SC 6 & 41062 & 379.5 & 0.099 & 46061 & 390.3 & 0.108 \\
\hline
\end{tabular}
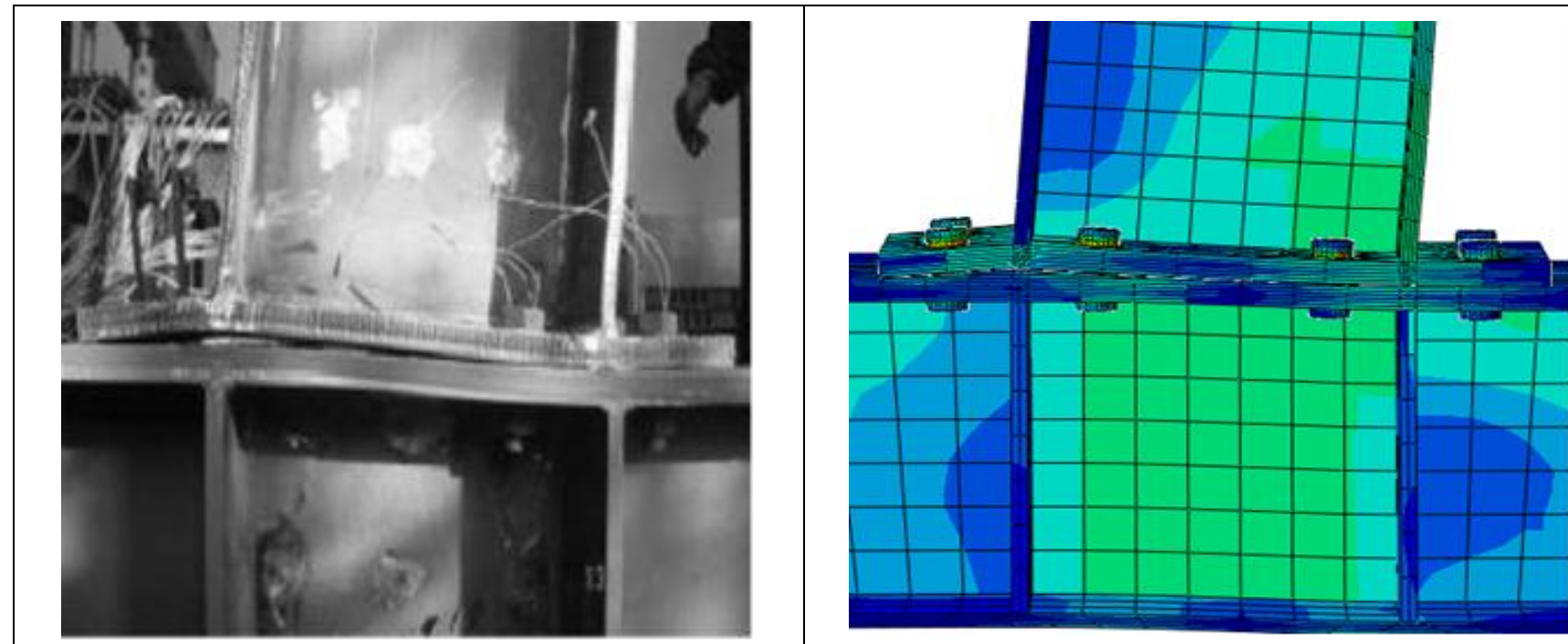

SC 3 Failure due to bolt fracture.
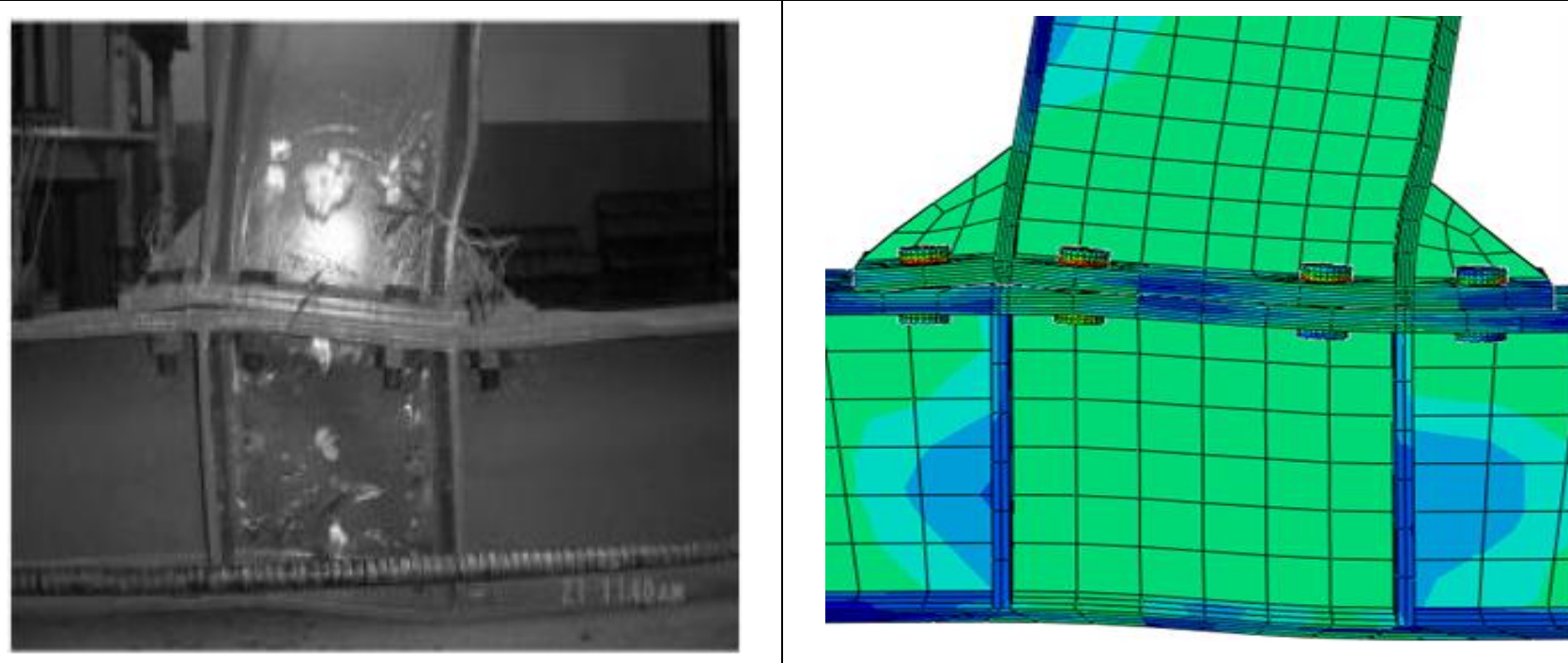

SC 6 Failure due to beam flange buckling

Fig. 5: Comparison of failure modes between FEM and the experimental result Shi et al. [9] for extended steel endplate connection specimens. 


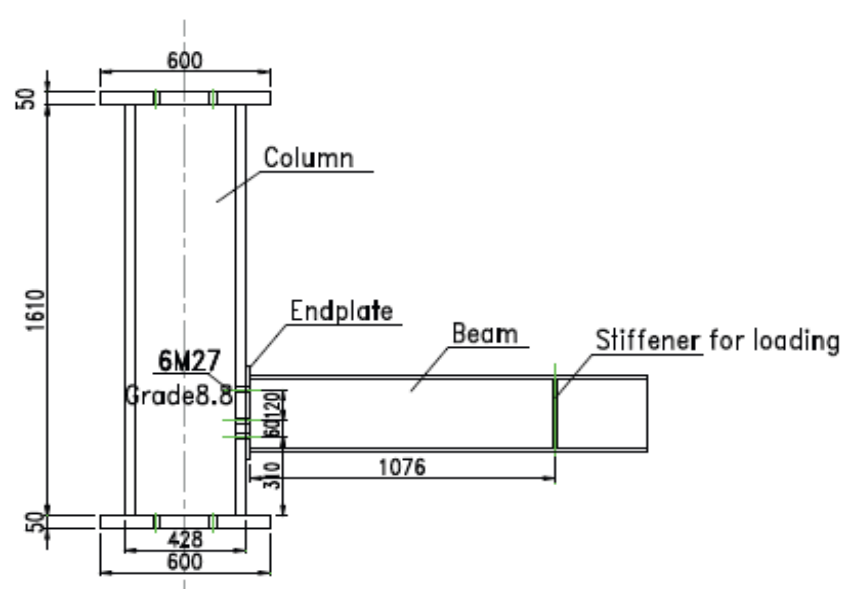

Figure 6. Flush endplate connection Qiang et al. [11].

The endplates were fabricated from S690 steel. For specimen (2-3 A) with thicknesses $15 \mathrm{~mm}$ but for specimen (2-4 A) the endplate was fabricated from S960 steel with thickness $12 \mathrm{~mm}$. In the contact interaction property, the friction coefficient between steel surfaces was estimated to be 0.44 . Figure 8 shows a comparison of numerical modelling and experimental research on the moment-rotation relationship of different beam-to-column endplate connections. Good agreements can be shown to exist in general.

The comparisons on final deformation states of connections at the end of the tests between numerical simulations and experimental results are shown in Fig. 9. It can be observed that good agreement exists on final deformation of connections. Although the current numerical model cannot simulate the fracture of the bolts, it is able to reveal the location where the fracture initiates and evolves.

\section{PARAMETRIC STUDY}

Upon validation of the FE models, parametric studies were performed to investigate the effect of different parameters on the behaviour of bolted extended end-plate connections. Therefore, the geometric parameters are selected and varied /within the comprehensive practical ranges of extended endplate connections. The material parameters used for the high strength endplates material were taken from Qiang's PhD thesis [12].

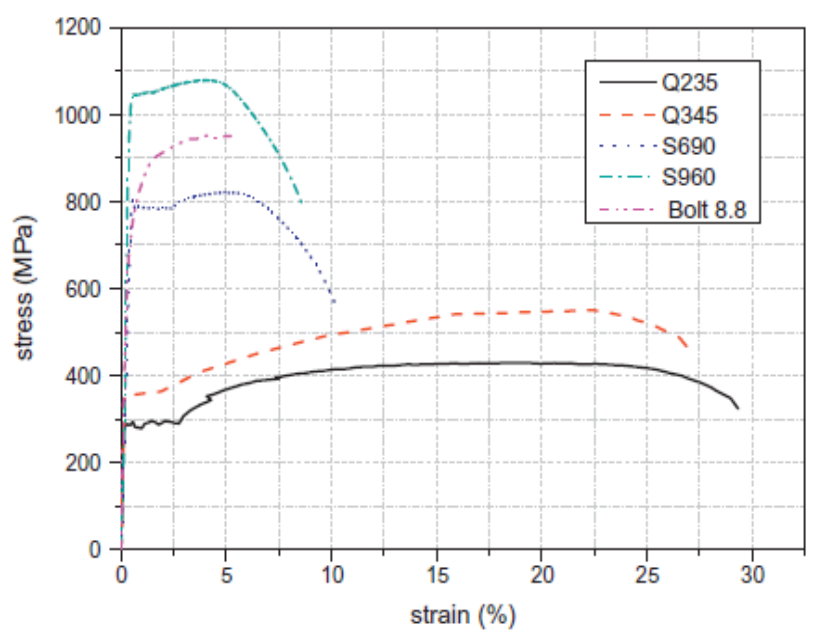

Figure 7. Stress - strain curves of various materials Qiang et al. [7].
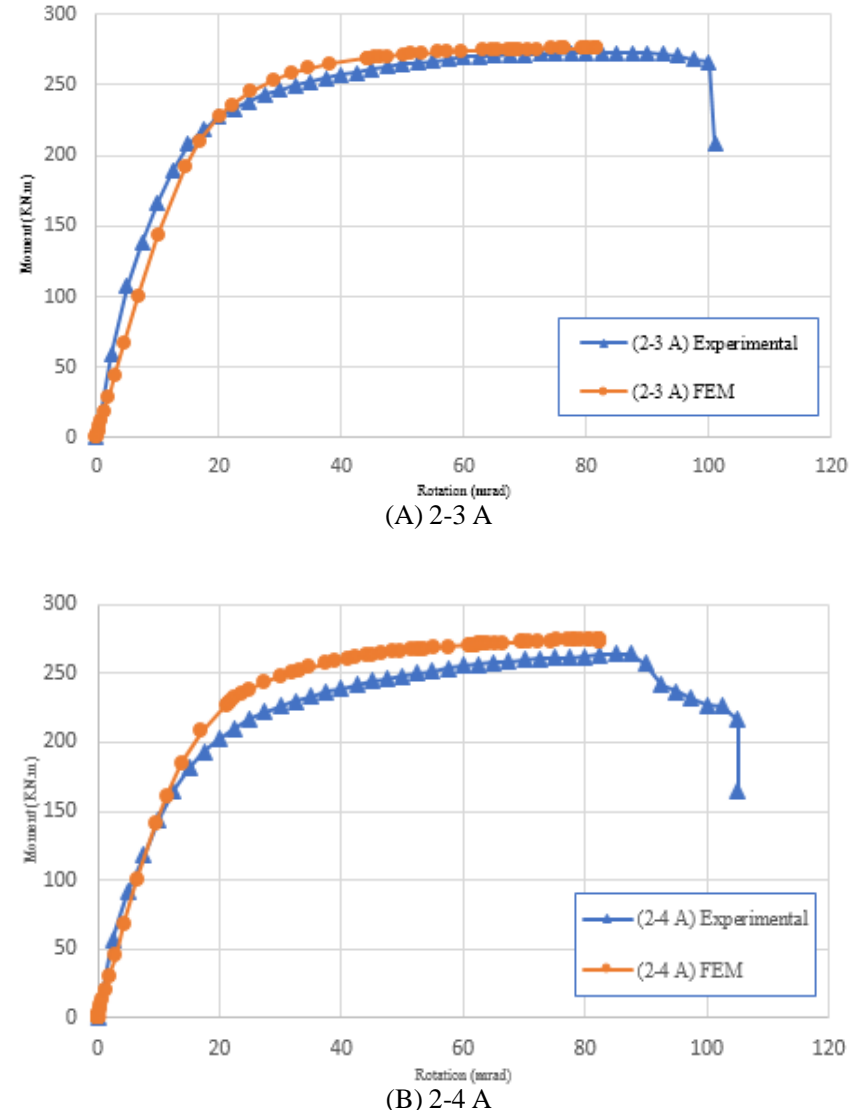

Figure 8. Comparison of measured results (by experimental work [11]) and predicted results (by FEM) for high steel endplate connection.

The parameters varied for the parametric studies include the thickness of the end plate, bolt diameter and steel grade of the endplate, as shown in Table 3. Only one parameter was changed at each group so as to clarify its effect.

\section{ANALYSIS OF RESULTS}

\section{A. Effect of endplate steel grade}

In this section, the effect of endplate steel grade (Q345, S460, S690, and S960) is discussed. Figure 10 shows the relationships between the moment and the rotation with different endplate thicknesses for extended endplate connections shown in Fig. 3.

As expected, increasing the endplate steel gradeleads to a marked increase of both the strength and the stiffness but reduced the ductility of the connections. Moreover, an increase in strength is accompanied by a corresponding decrease in the rotation at which the ultimate moment occurs. Comparing the response of the models with different endplate steel grades, it can be concluded that increasing the endplate steel grade exhibits higher strength but lower ductility.

\section{B. Effect of bolt diameter}

Figure 11 depicts the effect of bolt diameters on the initial stiffness, ultimate moment, and rotation capacity for the shown attachment form with three end-plate thickness values of 14,18 , and $28 \mathrm{~mm}$. It can be seen that increasing the bolt diameter and end plate thickness increases the initial stiffness, ultimate moment, and rotation. Specifically, for an end-plate with a moderate thickness of $18 \mathrm{~mm}$, increasing the bolt diameter from 20 to $24 \mathrm{~mm}$ increases the initial stiffness, 
ultimate moment, and rotation capacity by approximately $3.2 \%, 10.7 \%$, and $24 \%$, respectively.

\section{Effect of endplate thickness}

The effect of different endplate thicknesses on the initial stiffness, ultimate moment, and rotation capacity for the shown connection type is depicted in Fig. 12. End-plate thicknesses of 14, 18, and $28 \mathrm{~mm}$ are considered. The results are shown for bolt diameters of 20 and $24 \mathrm{~mm}$.

In general, the initial stiffness increases significantly as endplate thickness increases, although it increases slightly as bolt diameter increases. Furthermore, the bolt diameter and end-plate thickness have a significant impact on the ultimate moment and rotation capacity This may be because increasing the end-plate thickness allows more tensile force in the bolts, which increases the moment capacity, but the increase is not very significant and will cause brittle failure of the bolts with low rotation capacity of the connection.

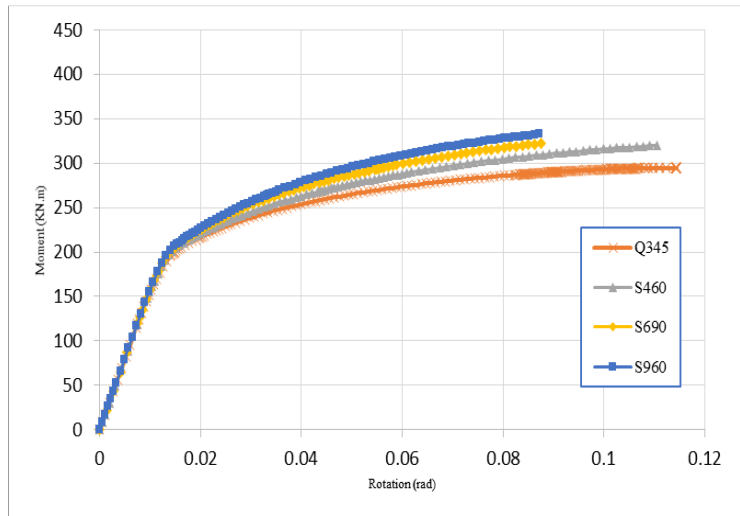

(a) $t_{p}=14 \mathrm{~mm}, D=20 \mathrm{~mm}$

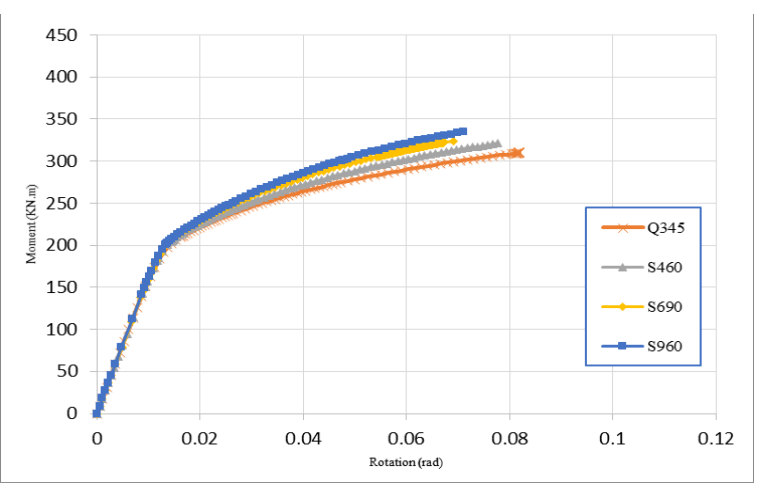

(b) $t_{p}=14 \mathrm{~mm}, D=24 \mathrm{~mm}$

Figure 10 Moment-rotation relationships of extended endplate connection with different endplate steel grades

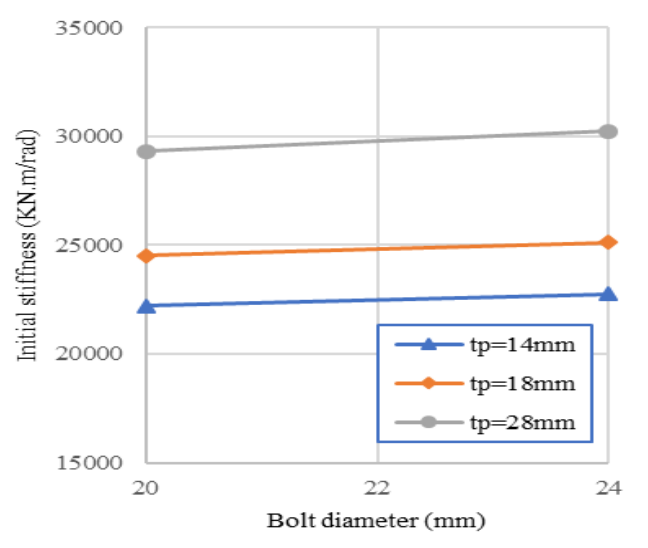

(a) Effect of bolt diameter on initial stiffness

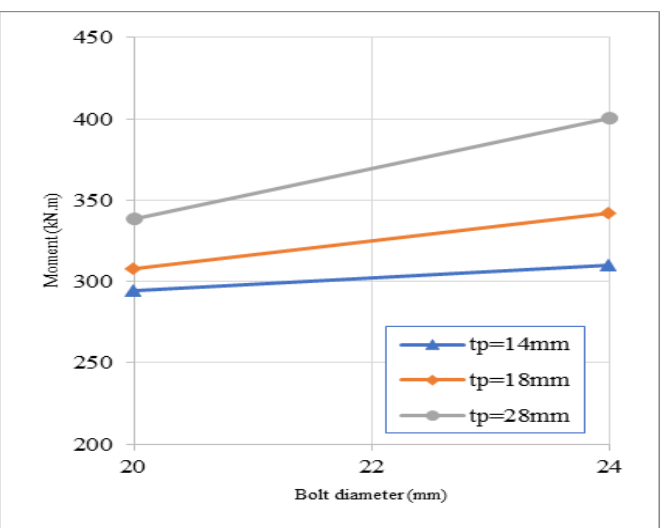

(b) Effect of bolt diameter on ultimate moment.

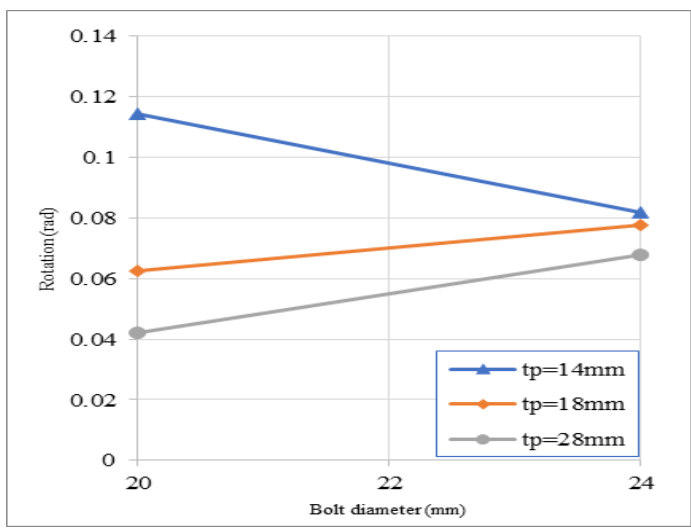

(c) Effect of bolt diameter on rotation capacity.

Figure 11. Effect of bolt diameter on initial stiffness, ultimate moment, and rotation capacity. 

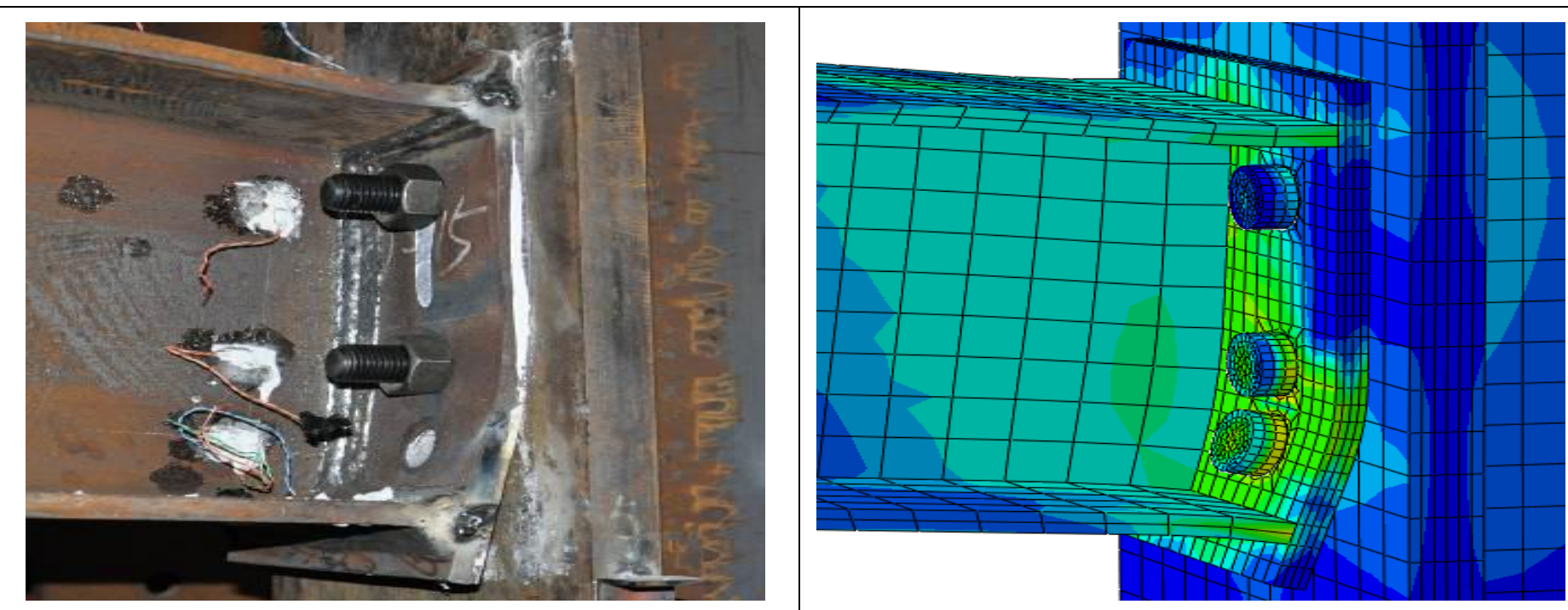

2-3 A bolt failure with yielding of the endplate
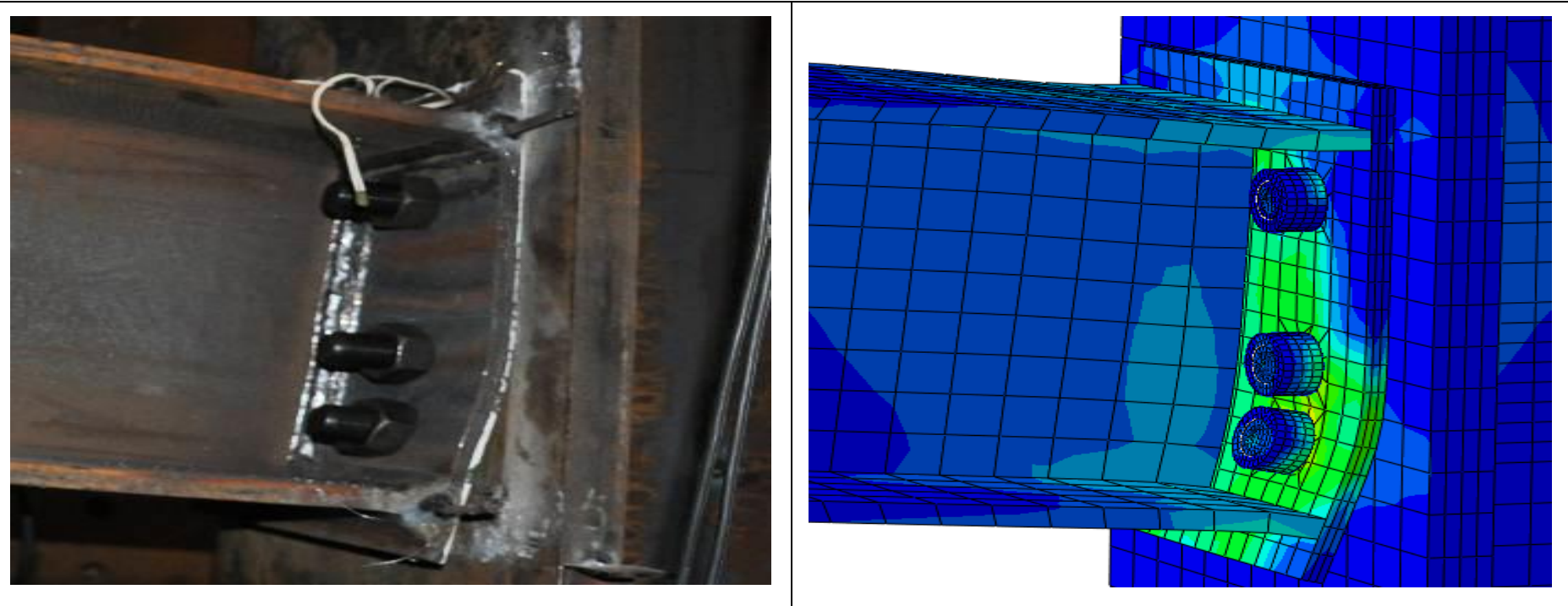

2-4 A bolt failure with yielding of the endplate

Figure 9 Comparison of failure modes between FEM and the experimental result Qiang et al. [11] for high strength steel endplate connection specimens

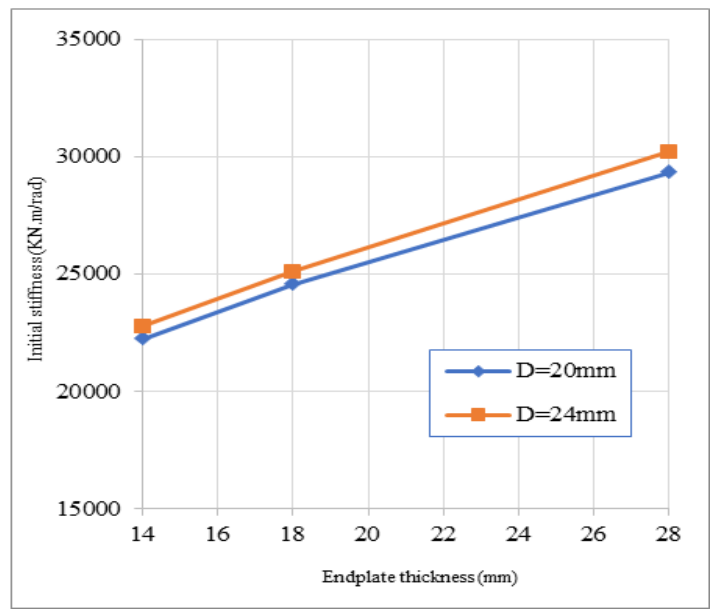

(a) Effect of endplate thickness on initial stiffness

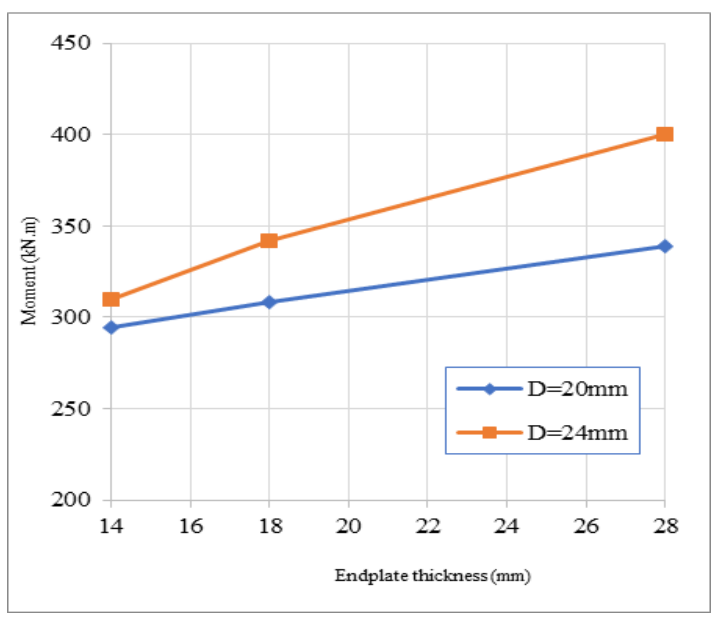

(b) Effect of endplate thickness on ultimate moment. 


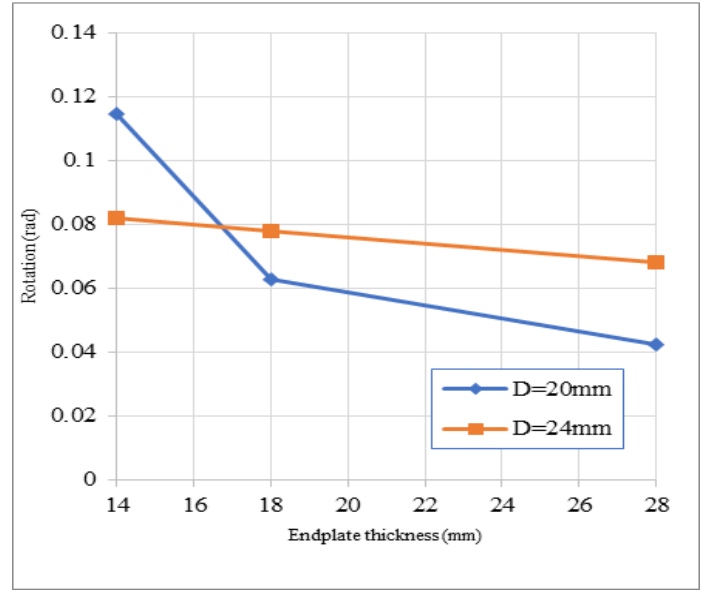

(c) Effect of endplate thickness on rotation capacity.

Figure 12. Effect of endplate thickness on initial stiffness, ultimate moment, and rotation capacity.

\section{CONCLUSIONS}

The aim of this research is to present a three-dimensional finite element (FE) model for the analysis of extended endplate mild and high strength steel connections subjected to monotonic loading with various types and details. Also, the effect of various parameters on connection behaviour is investigated. The following results are summarized for the cases studied in this research:

- Comparisons between experimental results and those obtained by the current FE model show that the current numerical model can simulate and predict the behaviour of bolted end-plate connections with good accuracy. The comparisons included the moment-rotation curves and the modes of failure.

- The results showed that for extended endplate connections, increasing the endplate thickness tp or the bolt diameter leads to a marked increase of both the strength and the stiffness but it reduces the ductility of the connections.

- When the responses of the models with different endplate steel grades are compared, it is possible to conclude that increasing the endplate steel grade results in higher strength but lower ductility.
- The initial stiffness increases significantly as endplate thickness increases, but only slightly as bolt diameter increases. Furthermore, the bolt diameter and end-plate thickness have a significant influence on the ultimate moment and rotation capacity.

\section{REFERENCES}

[1] EN 1993-1-8, Eurocode 3: Design of steel Structures - Part 1-8: Design of Joints, British Standards Institution, CEN, 2003.

[2] M. A Dabaon, M. A. Kassem, S. R. Elkhoreby and T. Khalifa, "Finite element modeling of extended end-plate connection subjected to static and cyclic loading." Twelfth International Colloquium on Structural and Geotechnical Engineering, Ain Shams University, Cairo, Egypt, 42(2), 2007.

[3] M. A. Dabaon, M. H. El-Boghdadi, and O. F. Kharoob, "Semirigid joints in bare steel and composite frames subjected to loading in space - Part II: Finite element modeling." Twelfth International Colloquium on Structural and Geotechnical Engineering, Cairo, Egypt, December 10-12, STL010, 2007.

[4] ANSYS Element reference manual, version 5.4, 000853. Ninth Edition, SAS IP,Ink.

[5] M. A. Dabaon, M. H. El-Boghdadi, and O. F. Kharoob, "Experimental and numerical model for space steel and composite semi-rigid joints." Journal of Constructional Steel Research, Vol. 65, pp. 1864-1875, 2009.

[6] G. Shi, Y Shi, Y Wang and Mark A. Bradfordb, "Numerical simulation of steel pretensioned bolted end-plate connections of different types and details.” Engineering Structures Vol. 30, No. 10, pp. 2677-2686, 2008.

[7] X. Qiang, FSK. Bijlaard, MH. Kolstein, X. Jiang. "Behaviour of beam-to-column high strength steel endplate connections under fire conditions - Part 2: Numerical study." Engineering Structures 64: pp. 39-51, 2014.

[8] ABAQUS, analysis user's manual, 6.14 version

[9] G. Shi., Y. Shi, Y. Wang, and F.S.K. Bijlaard, "Monotonic loading tests on semi-rigid end-plate connections with welded Ishaped columns and beams.", Advances in Structural Engineering, Vol. 13, No. 2, pp. 215-230, 2010.

[10] A. M. Coelho and F.S.K. Bijlaard "Experimental behaviour of high strength steel end-plate connections." Journal of Constructional Steel Research Vol. 63, No. 9, pp. 1228-1240, 2007.

[11] X. Qiang, FSK. Bijlaard, MH. Kolstein, X. Jiang. "Behaviour of beam-to-column high strength steel endplate connections under fire conditions - Part 1: Experimental study." Engineering Structures 64: pp. 23-38, 2014.

[12] X. Qiang. "Behaviour of high strength steel endplate connections in fire and after fire." Ph.D. Thesis. Delft, the Netherlands: Delft University of Technology; 2013.

TABLE 3

PARAMETRIC STUDIES (GEOMETRY AND RESULTS)

\begin{tabular}{|c|c|c|c|c|c|c|c|c|c|c|c|c|c|c|c|}
\hline \multicolumn{3}{|c|}{ Column } & \multicolumn{3}{|c|}{ Beam } & \multicolumn{3}{|c|}{ End plate } & \multirow{2}{*}{$\begin{array}{c}\text { Bolt } \\
\text { Diameter } \\
(\mathrm{mm})\end{array}$} & \multicolumn{6}{|c|}{ End plate $\left(f_{y}=345 \mathrm{MPa}\right)$} \\
\hline $\begin{array}{c}t_{f c} \\
(m m)\end{array}$ & $\begin{array}{c}t_{w c} \\
(\mathrm{~mm})\end{array}$ & $\begin{array}{c}h_{c} \\
(\mathrm{~mm})\end{array}$ & $\begin{array}{c}t_{f b} \\
(m m)\end{array}$ & $\begin{array}{c}t_{w b} \\
(\mathrm{~mm})\end{array}$ & $\begin{array}{c}h_{b} \\
(\mathrm{~mm})\end{array}$ & $\begin{array}{c}t_{p} \\
(\mathrm{~mm})\end{array}$ & $\begin{array}{c}h_{p} \\
(m m)\end{array}$ & $\begin{array}{c}b_{p} \\
(m m)\end{array}$ & & $\begin{array}{c}M_{\max } \\
(K N . m)\end{array}$ & $\begin{array}{c}M_{J} \\
(K N . m)\end{array}$ & $\begin{array}{c}S_{J} \\
(k N . m / r a d)\end{array}$ & $\begin{array}{c}\Phi_{J} \\
(\mathrm{rad})\end{array}$ & $\begin{array}{l}\varphi_{\max } \\
(\mathrm{rad})\end{array}$ & $\begin{array}{c}\text { ductillity } \\
\text { index } \\
\psi_{j}=\frac{\phi_{\max }}{\phi_{M_{R d}}}\end{array}$ \\
\hline 12 & 8 & 300 & 12 & 8 & 300 & 14 & 500 & 200 & 20 & 294 & 211 & 22200 & 0.0095 & 0.114 & 12.048 \\
\hline 12 & 8 & 300 & 12 & 8 & 300 & 18 & 500 & 200 & 20 & 308 & 215 & 24520 & 0.0081 & 0.063 & 7.732 \\
\hline 12 & 8 & 300 & 12 & 8 & 300 & 28 & 500 & 200 & 20 & 338 & 235 & 29302 & 0.0080 & 0.042 & 5.271 \\
\hline 12 & 8 & 300 & 12 & 8 & 300 & 14 & 500 & 200 & 24 & 309 & 212 & 22767 & 0.0093 & 0.082 & 8.809 \\
\hline
\end{tabular}




\begin{tabular}{|c|c|c|c|c|c|c|c|c|c|c|c|c|c|c|c|}
\hline 12 & 8 & 300 & 12 & 8 & 300 & 18 & 500 & 200 & 24 & 341 & 217 & 25126 & 0.0089 & 0.078 & 8.729 \\
\hline 12 & 8 & 300 & 12 & 8 & 300 & 22 & 500 & 200 & 24 & 363 & 228 & 27021 & 0.0084 & 0.071 & 8.496 \\
\hline 12 & 8 & 300 & 12 & 8 & 300 & 28 & 500 & 200 & 24 & 400 & 251 & 30222 & 0.0081 & 0.068 & 8.378 \\
\hline
\end{tabular}

\begin{tabular}{|c|c|c|c|c|c|c|c|c|c|c|c|c|c|c|c|}
\hline \multicolumn{3}{|c|}{ Column } & \multicolumn{3}{|c|}{ Beam } & \multicolumn{3}{|c|}{ End plate } & \multirow{2}{*}{$\begin{array}{c}\text { Bolt } \\
\text { Diameter } \\
(\mathrm{mm})\end{array}$} & \multicolumn{6}{|c|}{ End plate $\left(f_{y}=460 \mathrm{MPa}\right)$} \\
\hline $\begin{array}{c}t_{f c} \\
(\mathrm{~mm})\end{array}$ & $\begin{array}{c}t_{w c} \\
(\mathrm{~mm})\end{array}$ & $\begin{array}{c}h_{c} \\
(\mathrm{~mm})\end{array}$ & $\begin{array}{c}t_{f b} \\
(\mathrm{~mm})\end{array}$ & $\begin{array}{c}t_{w b} \\
(m m)\end{array}$ & $\begin{array}{c}h_{b} \\
(\mathrm{~mm})\end{array}$ & $\begin{array}{c}t_{p} \\
(\mathrm{~mm})\end{array}$ & $\begin{array}{c}h_{p} \\
(\mathrm{~mm})\end{array}$ & $\begin{array}{c}b_{p} \\
(\mathrm{~mm})\end{array}$ & & $\begin{array}{c}M_{\max } \\
(K N . m)\end{array}$ & $\begin{array}{c}M_{J} \\
(K N . m)\end{array}$ & $\begin{array}{c}S_{J} \\
(k N . m / r a d)\end{array}$ & $\begin{array}{c}\Phi_{J} \\
(\mathrm{rad})\end{array}$ & $\begin{array}{l}\varphi_{\max } \\
(\mathrm{rad})\end{array}$ & $\begin{array}{c}\text { ductillity } \\
\text { index } \\
\psi_{j}=\frac{\phi_{\max }}{\phi_{M_{R d}}}\end{array}$ \\
\hline 12 & 8 & 300 & 12 & 8 & 300 & 14 & 500 & 200 & 20 & 320 & 226 & 22522 & 0.0100 & 0.110 & 11.050 \\
\hline 12 & 8 & 300 & 12 & 8 & 300 & 18 & 500 & 200 & 20 & 323 & 228 & 25012 & 0.0098 & 0.067 & 7.721 \\
\hline 12 & 8 & 300 & 12 & 8 & 300 & 28 & 500 & 200 & 20 & 339 & 260 & 29952 & 0.0080 & 0.042 & 5.266 \\
\hline 12 & 8 & 300 & 12 & 8 & 300 & 14 & 500 & 200 & 24 & 321 & 240 & 23077 & 0.0092 & 0.078 & 8.458 \\
\hline 12 & 8 & 300 & 12 & 8 & 300 & 18 & 500 & 200 & 24 & 349 & 313 & 25750 & 0.0090 & 0.071 & 7.861 \\
\hline 12 & 8 & 300 & 12 & 8 & 300 & 22 & 500 & 200 & 24 & 373 & 324 & 27560 & 0.0091 & 0.068 & 7.480 \\
\hline 12 & 8 & 300 & 12 & 8 & 300 & 28 & 500 & 200 & 24 & 404 & 351 & 30570 & 0.0082 & 0.055 & 6.749 \\
\hline
\end{tabular}

\begin{tabular}{|c|c|c|c|c|c|c|c|c|c|c|c|c|c|c|c|}
\hline \multicolumn{3}{|c|}{ Column } & \multicolumn{3}{|c|}{ Beam } & \multicolumn{3}{|c|}{ End plate } & \multirow{2}{*}{$\begin{array}{c}\text { Bolt } \\
\begin{array}{c}\text { Diameter } \\
(\mathrm{mm})\end{array}\end{array}$} & \multicolumn{6}{|c|}{ End plate $\left(f_{y}=690 \mathrm{MPa}\right)$} \\
\hline $\begin{array}{c}t_{f c} \\
(m m \\
)\end{array}$ & $\begin{array}{c}t_{w c} \\
(\mathrm{~mm})\end{array}$ & $\begin{array}{c}h_{c} \\
(\mathrm{~mm})\end{array}$ & $\begin{array}{c}t_{f b} \\
(\mathrm{~mm})\end{array}$ & $\begin{array}{c}t_{w b} \\
(m m)\end{array}$ & $\begin{array}{c}h_{b} \\
(\mathrm{~mm})\end{array}$ & $\begin{array}{c}t_{p} \\
(m m)\end{array}$ & $\begin{array}{c}h_{p} \\
(\mathrm{~mm})\end{array}$ & $\begin{array}{c}b_{p} \\
(m m)\end{array}$ & & $\begin{array}{c}M_{\max } \\
(K N . m)\end{array}$ & $\begin{array}{c}M_{J} \\
(K N . m)\end{array}$ & $\begin{array}{c}S_{J} \\
(\mathrm{kN} . \mathrm{m} / \mathrm{rad})\end{array}$ & $\begin{array}{c}\Phi_{J} \\
(\mathrm{rad})\end{array}$ & $\begin{array}{l}\varphi_{\max } \\
(\mathrm{rad})\end{array}$ & $\begin{array}{c}\text { ductillity } \\
\text { index } \\
\psi_{j}=\frac{\phi_{\max }}{\phi_{M_{R d}}}\end{array}$ \\
\hline 12 & 8 & 300 & 12 & 8 & 300 & 14 & 500 & 200 & 20 & 322 & 235 & 22750 & 0.0089 & 0.087 & 9.833 \\
\hline 12 & 8 & 300 & 12 & 8 & 300 & 18 & 500 & 200 & 20 & 327 & 255 & 25420 & 0.0088 & 0.061 & 6.940 \\
\hline 12 & 8 & 300 & 12 & 8 & 300 & 28 & 500 & 200 & 20 & 340 & 266 & 30240 & 0.0080 & 0.042 & 5.225 \\
\hline 12 & 8 & 300 & 12 & 8 & 300 & 14 & 500 & 200 & 24 & 324 & 247 & 23302 & 0.0090 & 0.069 & 8.296 \\
\hline 12 & 8 & 300 & 12 & 8 & 300 & 18 & 500 & 200 & 24 & 361 & 317 & 26304 & 0.0091 & 0.068 & 7.534 \\
\hline 12 & 8 & 300 & 12 & 8 & 300 & 22 & 500 & 200 & 24 & 389 & 335 & 27950 & 0.0088 & 0.065 & 7.439 \\
\hline 12 & 8 & 300 & 12 & 8 & 300 & 28 & 500 & 200 & 24 & 405 & 364 & 30882 & 0.0080 & 0.053 & 6.612 \\
\hline
\end{tabular}

\begin{tabular}{|c|c|c|c|c|c|c|c|c|c|c|c|c|c|c|c|}
\hline \multicolumn{3}{|c|}{ Column } & \multicolumn{3}{|c|}{ Beam } & \multicolumn{3}{|c|}{ End plate } & \multirow{2}{*}{$\begin{array}{c}\text { Bolt } \\
\begin{array}{c}\text { Diameter } \\
(\mathrm{mm})\end{array}\end{array}$} & \multicolumn{6}{|c|}{ End plate $\left(f_{y}=960 \mathrm{MPa}\right)$} \\
\hline $\begin{array}{c}t_{f c} \\
(\mathrm{~mm})\end{array}$ & $\begin{array}{c}t_{w c} \\
(m m)\end{array}$ & $\begin{array}{c}h_{c} \\
(\mathrm{~mm})\end{array}$ & $\begin{array}{c}t_{f b} \\
(\mathrm{~mm})\end{array}$ & $\begin{array}{c}t_{w b} \\
(m m)\end{array}$ & $\begin{array}{c}h_{b} \\
(\mathrm{~mm})\end{array}$ & $\begin{array}{c}t_{p} \\
(m m)\end{array}$ & $\begin{array}{c}h_{p} \\
(\mathrm{~mm})\end{array}$ & $\begin{array}{c}b_{p} \\
(\mathrm{~mm})\end{array}$ & & $\begin{array}{c}M_{\max } \\
(K N . m)\end{array}$ & $\begin{array}{c}M_{J} \\
(K N . m)\end{array}$ & $\begin{array}{c}S_{J} \\
(\mathrm{kN} . \mathrm{m} / \mathrm{rad})\end{array}$ & $\begin{array}{c}\Phi_{J} \\
(\mathrm{rad})\end{array}$ & $\begin{array}{c}\varphi_{\max } \\
(\mathrm{rad})_{x}\end{array}$ & $\begin{array}{c}\text { ductillity } \\
\text { index } \\
\psi_{j}=\frac{\phi_{\max }}{\phi_{M_{R d}}}\end{array}$ \\
\hline 12 & 8 & 300 & 12 & 8 & 300 & 14 & 500 & 200 & 20 & 332 & 286 & 23020 & 0.0097 & 0.087 & 8.995 \\
\hline 12 & 8 & 300 & 12 & 8 & 300 & 18 & 500 & 200 & 20 & 340 & 307 & 25722 & 0.0092 & 0.060 & 6.563 \\
\hline 12 & 8 & 300 & 12 & 8 & 300 & 28 & 500 & 200 & 20 & 348 & 316 & 30504 & 0.0080 & 0.040 & 5.049 \\
\hline 12 & 8 & 300 & 12 & 8 & 300 & 14 & 500 & 200 & 24 & 335 & 315 & 24942 & 0.0095 & 0.071 & 7.489 \\
\hline 12 & 8 & 300 & 12 & 8 & 300 & 18 & 500 & 200 & 24 & 369 & 326 & 26920 & 0.0092 & 0.066 & 7.160 \\
\hline 12 & 8 & 300 & 12 & 8 & 300 & 22 & 500 & 200 & 24 & 394 & 361 & 28252 & 0.0090 & 0.063 & 7.010 \\
\hline 12 & 8 & 300 & 12 & 8 & 300 & 28 & 500 & 200 & 24 & 405 & 367 & 31122 & 0.0088 & 0.053 & 6.010 \\
\hline
\end{tabular}

